\title{
Design and Construction of an Automatic Home and Office Power Control System
}

\author{
*Ayinde M. Usman, Oladimeji Ibrahim, Yaro S. Muhammed, Abdulrahaman O. Otuoze, \\ Sikiru O. Zakariyya, and Mubarak A. Afolayan \\ Department of Electrical and Electronics Engineering, University of Ilorin, Nigeria \\ \{usman.am |ibrahim.o | otuoze.ao | zakariyyah.os | afolayan.ma \}@unilorin.edu.ng | yasmud99@gmail.com
}

Received: 01-JAN-2021; Reviewed: 21-FEB-2021; Accepted: 06-APR-2021

http://dx.doi.org/10.46792/fuoyejet.v6i2.597

\begin{abstract}
In homes and offices, it is very common for occupants to forget to switch OFF the lighting and fans when leaving the premises. This can be attributed to human forgetfulness and the epileptic power supply which causes interruption that results in users forgetting the state of their appliances (whether they are ON or OFF). Consequently, these appliances would continue to work whenever power is restored when the occupants might have vacated the premise. This action is not a small contributor to energy wastage in a country like Nigeria where there is an inadequate energy supply to go round the populace. In this work, a simple but robust automatic home and office power control system is developed to auto-detect the presence of an occupant in the room through the passive infrared (PIR) sensor and control the electrical appliances (lighting and fan source) in the room. Certain conditions must be met for the operation of lighting and the fan source. The lighting comes up when the PIR sensor senses the presence of an occupant and the room is in darkness, while the fan would work when there is an occupant and the temperature in the room is above $35^{\circ} \mathrm{C}$. These conditions are programmed to suit the need of the occupant but cannot be changed by the user. The device automatically switches OFF within five minutes after the last occupant leaves the room.
\end{abstract}

Keywords- Home Automation, Microcontroller, Passive infrared (PIR) sensor, Solid State Relay (SSR), and Switching

\section{INTRODUCTION}

$\mathrm{T}$ he inadequate availability of electrical power supply

in Nigeria has continued to negatively impact the lives of her people. The energy production in Nigeria is abysmally low (Johnson et al., 2020) to meet the need of the population. The electricity demand kept increasing annually (Mohammed et al., 2020; Otuoze et al., 2017) because of the increase in population growth, and the productions of new devices depending on electricity for operation. Despite the variance between demand and supply, there are reported wastages and misuse of the limited supplied electricity (Adelakun et al., 2014). Hence, there is a need to propose more ways to increase energy conservation policy in the country.

Electrical appliances, particularly lighting points are often left $\mathrm{ON}$ even when no one is in the room or office. Many electrical consumers in Nigeria waste the little available electrical supply with no plan for conservation (Adelakun et al., 2014). The wastages can also be attributed to the epileptic power supply which causes interruption that results in users forgetting the state of their appliances (whether they are $\mathrm{ON}$ or OFF). These appliances continue to run when power is restored, even when the user has left the premises. Ehiabhili et al., (2020) developed an automated home control system using wireless Bluetooth technology that interface between the electrical appliance switch and Android smartphone. However, their work focused more on the automation of switching systems rather than energy conservation.

\section{${ }^{*}$ Corresponding Author}

Section B- ELECTRICAL/COMPUTER ENGINEERING \& COMPUTING SCIENCES Can be cited as:

Usman A.M., Ibrahim O., Muhammed Y.S., Otuoze A.O., Zakariyya O.S., and Afolayan M.A. (2021): Design and Construction of an Automatic Home and Office Power Control System, FUOYE Journal of Engineering and Technology (FUOYEJET), 6(2), 25-29. http://dx.doi.org/10.46792/fuoyejet.v6i2.597
Iromini et al., (2015) designed an automatic switch controller which switches ON the lighting system in the office when the room illumination falls below a predetermined value with no consideration of whether there is an occupant in the office or not. This eventually leads to power wastages if there is no occupant in the room. This work proposes a simple but robust solution that would contribute to energy conservation with the design and construction of an automatic power control system using the solid-state relay (SSR). The device works using a passive infrared (PIR) sensor to determine the presence of a person in the room or office, relates the instantaneous condition of the room or office with set values to effectively control or regulate the appliances. The PIR sensor uninterruptedly monitors the room and sends a signal to the microcontroller whenever the presence of a person is detected. The device is programmed to switch ON or OFF the lighting points and fans subject to certain conditions. Finally, the system automatically switches off within five minutes after the last occupant leaves the premises, thus reducing energy wastage and associated cost.

The remainder of this paper is organized as follows. In Section 2, the design and implementation process is explained while results and discussion are presented in Section 3. The work is concluded with discernible explanations in Section 4.

\section{DESIGN AND IMPLEMENTATION}

The proposed system comprises various units such as the power supply unit (PSU), comparator unit, thermal unit, photo sensing unit, PIR unit, control unit, and switching unit. Overall, the various units comprise of the following electrical components: transformer, rectifier, resistor, diode, capacitor, amplifier, thermistor, PIR sensor, temperature sensor, illumination sensor, and solid-state relays (SSR) which are integrated using electrical design concept. These design concepts include theoretical calculations, assembly of components using physical 
assembly on a breadboard and then the Vero board, soldering, testing for continuity of the various components and units, as well as programming of the microcontroller.

Figure 1 shows the block diagram of an automatic home and office power control system. The interconnections between various units are indicated in the diagram.

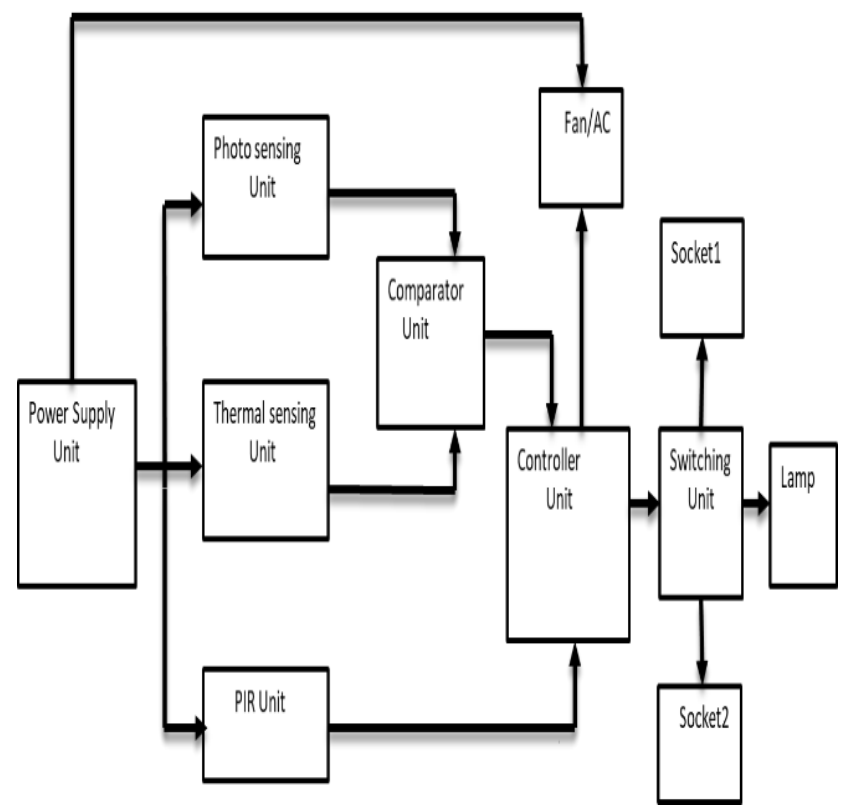

Fig. 1: Block Diagram of an Automatic Home/Office Control System

\subsection{POWER SUPPLY UNIT}

The power supply unit (PSU) transforms the $240 \mathrm{~V}$ Alternative Current (AC) supply from the mains to $5 \mathrm{~V}$ which is the required voltage level by other units in the system. It consists of a stepdown transformer, diodes, filtering capacitor, and voltage regulator. The $240 \mathrm{~V}$ from the mains is stepdown to $12 \mathrm{~V} \mathrm{AC}$ which is then passed through the bridge rectifier to obtain the corresponding Direct Current (DC) voltage. But the DC voltage produced contains some ripples. These ripples are filtered off by the filtering capacitor. The filtered voltage is passed through the LM7805 (Shawn, 2019) voltage regulator to obtain 5 V DC needed to power the system.

\subsection{COMPARATOR UNIT}

The comparator unit was achieved with the aid of an operational amplifier LM385 (Ashutosh, 2018) integrated circuit (IC). The LM385 is used to determine the logical status of the photosensor and the thermal sensor.

\section{3 Рhoto Sensing UNIT}

The Light Dependent Resistor (LDR) is used to achieve the photo sensing unit of the system. The LDR which is also known as a photo-resistor is a component whose resistance increases as darkness increases. Thus, it is used to indicate the presence or absence of light. This is achieved with the interconnection of LDR, $100 \mathrm{k} \Omega$ resistor, potentiometer, and comparator. The resistance of the LDR was measured during daylight and it was observed to be $100 \mathrm{k} \Omega$. The potentiometer was adjusted to obtain $2.5 \mathrm{~V}$ at the inverting terminal and LDR was connected in parallel to the non-inverting terminal such that voltage drop across LDR is equal to the voltage at the non-inverting terminal. When room illumination increases, LDR resistance increases, and the voltage drop across it increase. Therefore, the non-inverted terminal voltage increases with a decrease in room illumination and whenever non-inverted voltage is higher than inverted terminal voltage, a high output signal is sent to the microcontroller to energize the relay, thus putting the PIR sensor in a high state (logic ' 1 ').

\subsection{THERMAL SENSING UNIT}

In this unit, the instantaneous room temperature is compared with a preset temperature value to send the signal to the controller to activate the appropriate relay (switch). A $1 \mathrm{k} \Omega$ Negative Temperature Coefficient (NTC) thermistor, potentiometer, and $1 \mathrm{k} \Omega$ resistor are connected to achieve this unit. The potentiometer is adjusted to supply $2.5 \mathrm{~V}$ to the inverting terminal of the comparator and the $1 \mathrm{k} \Omega$ is connected in parallel to the non-inverting terminal such that voltage at the noninverting terminal is equal to the voltage drop across the $1 \mathrm{k} \Omega$ resistor. When the room temperature rises, thermistor resistance decreases, and consequently, the voltage drop across it decreases. In order to maintain a $5 \mathrm{~V}$ drop across the thermistor and $1 \mathrm{k} \Omega$ resistor, voltage drop across the $1 \mathrm{k} \Omega$ resistor increases to balance for any decrease in the voltage drop across the thermistor. This results in an increase in voltage at the non-inverting terminal, and the comparator gives a high output whenever the voltage at the non-inverting terminal is higher than that of the inverting terminal.

\subsection{PIR SENSOR UNIT}

The PIR is a sensor designed to sense the presence of human being within a radius of its field-of-view (Odat et al., 2017). It senses human presence by measuring infrared light reflecting from its field. The light reflecting from its field changes with the presence of human being. Initially, the module output is low (logic 0). However, when human presence is sensed, the module output changes to high (logic 1$)$. A pictorial view of a PIR sensor is shown in Figure 2.

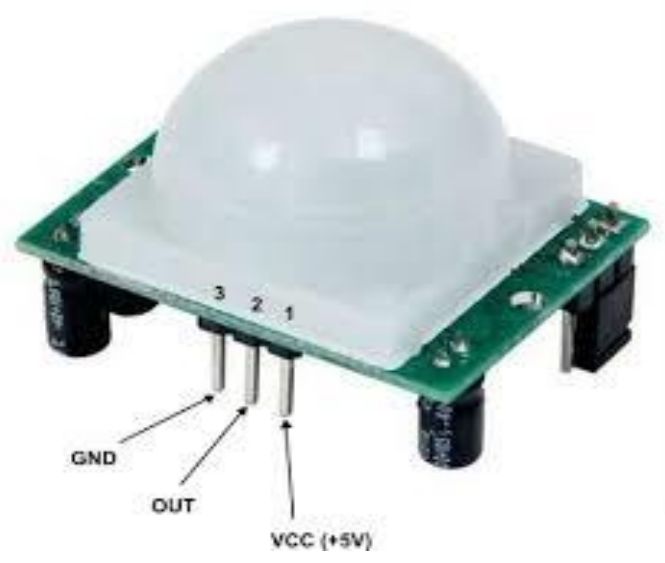

Fig. 2: Pictorial view of the PIR sensor 


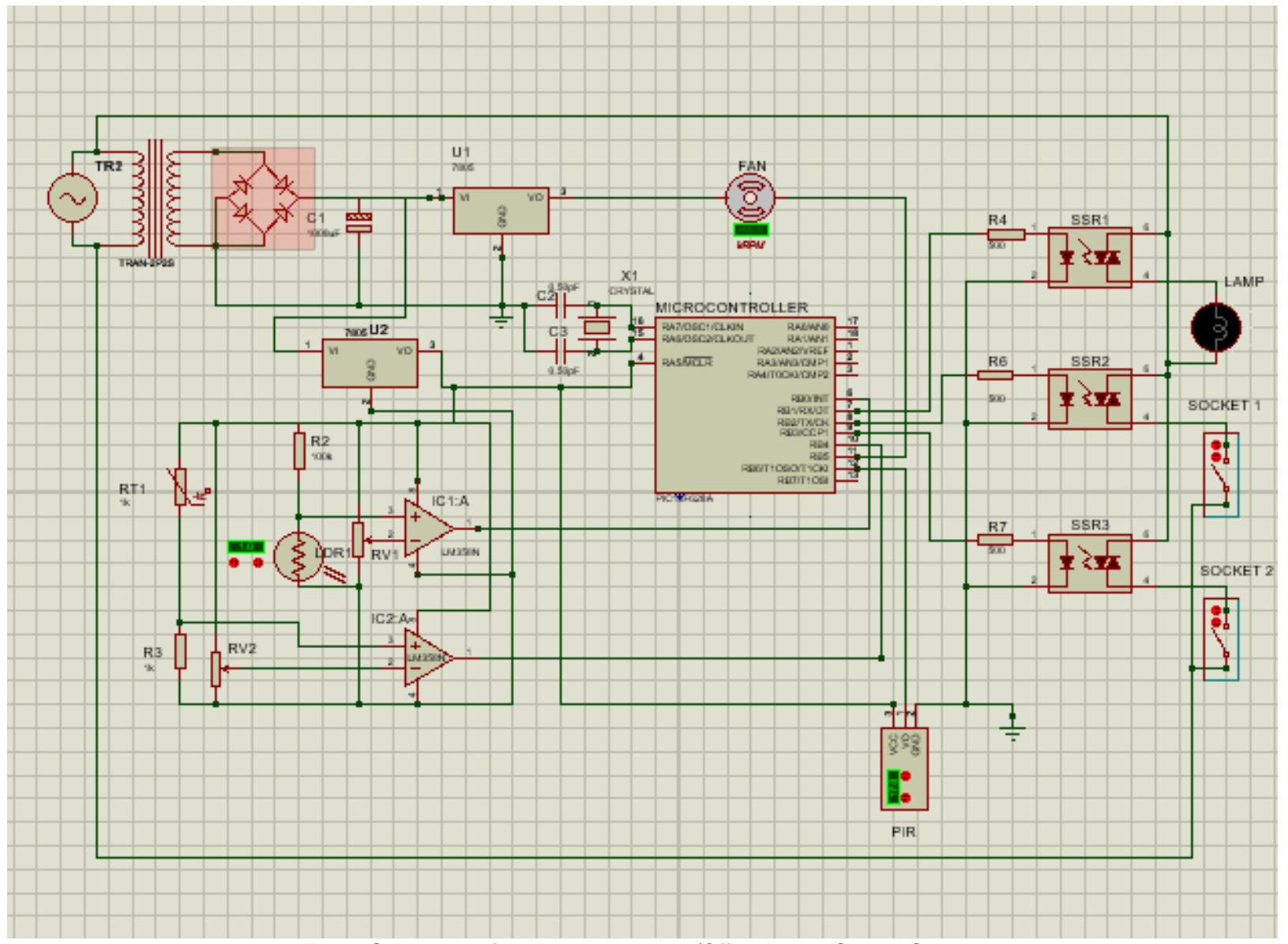

Fig. 3: Schematic of an Automatic Home/Office Power Control System

\subsection{CONTROLLER UNIT}

The PIC16F628A microcontroller is used to accomplish the controller unit. PIC16F628A is a tiny chip that comprises of processor, memory, I/O pins, other peripherals (Rezoug \& Krama, 2016). Besides, it is quite cheap with high-performance output. The controller is powered with $5 \mathrm{~V}$ and operates at $11.0952 \mathrm{MHz}$. It gets signals from various sensors and sends control signals to the appropriate relays through its output. The microcontroller unit is an essential part of the device. It is the interface between the sensors and the SSR in deciding the appropriate time to switch ON/OFF the lighting points and the appliances. The microcontroller was programmed using embedded C language (Pont, 2002).

\subsection{SWITCHING UNIT}

The switching unit was set-up using the SSR. The SSR is an electronic switching device that turns ON or OFF when a small voltage is passed across its control terminals. There are different types of SSR (Rezoug \& Krama, 2016), a photo coupled type is deployed in this work. In this project, the PIC16F628A microcontroller supplies the activation signal to the SSR based on a preset condition (as programmed in the Read-Only Memory (ROM) of the microcontroller) to allow passage of current to the connected load.

\subsection{LOAD UNIT}

In this device, lighting points and sockets control of fans make up the load unit. The loads switch ON or OFF subject to certain conditions as explained later in the text. The complete schematic circuit diagram of the system is shown in Figure 3 comprising of all the units.

\subsection{IMPLEMENTATION}

The implementation stage involves the assembling together of the different units and ensuring that the device works by the planned design. The components are assembled initially on the breadboard to determine the operability of the design. Test of the expected output of different sub-units was carried out to ensure it works as designed. Then, they are permanently soldered using the soldering iron and lead on the Vero board after the working has been tested and confirmed on the breadboard. The soldering process was done following standard soldering principles as stated in the work of Chia et al., (2018). This is to ensure good harmonious electrical and mechanical connectivity among the components and units. The flowchart of the designed automatic home and office power control system is shown in Figure 4. The system was packaged into a plastic casing which serves as the housing unit. The casing is to enable the device to be able to withstand mechanical shocks and vibration. 


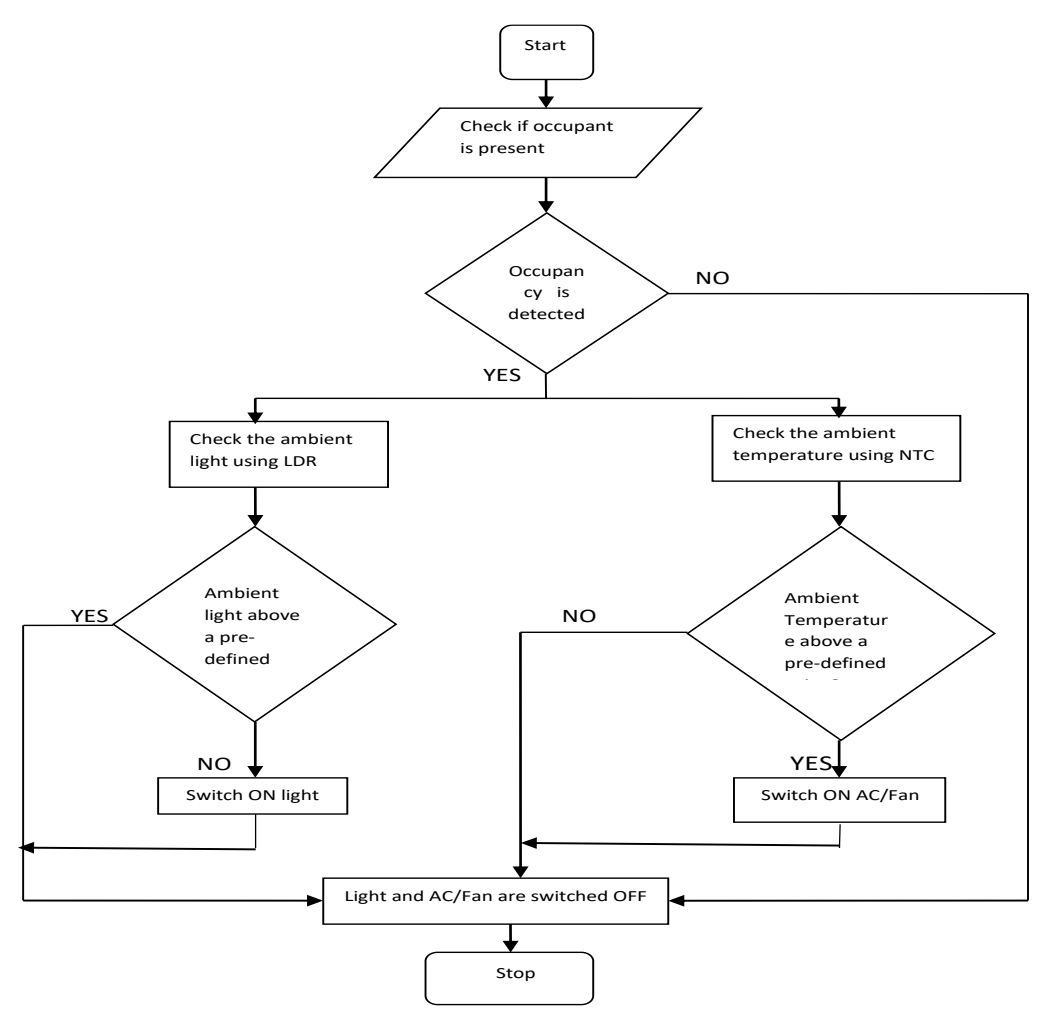

Fig. 4: Flowchart of an Automatic Home and Office Power Control System

\section{Results AND DISCUSSION}

The developed system was tested using three loads output; a socket point for powering the fan, two lighting points- bulb $\mathrm{A}$ which represents the regular room bulb while bulb B is used to represent the presence or absence of an occupant in the room. When a 210-240 V AC power is supplied to the device, its PSU gives a 5 V DC output that is regulated as explained earlier. A preliminary test to check if the LDR and the temperature sensing unit are performing as expected was carried out. When there is a light ray, and the power button was switched ON and the bulbs did not turn ON. The LDR was then shielded from light rays, the bulbs turned $\mathrm{ON}$ and went $\mathrm{OFF}$ immediately after the shield was removed from the LDR. The socket which is to power ON the fan whenever the room temperature increases above normal room temperature $\left(27^{\circ} \mathrm{C}\right)$ is controlled by the temperature sensing unit of the device. The fan started running as soon as the thermistor senses higher temperature above the room temperature, typically from above $35^{\circ} \mathrm{C}$ (which for testing purpose was achieved by bringing the thermistor close to the lit bulb). These different illustrations are shown in Figures 5, 6, and 7.

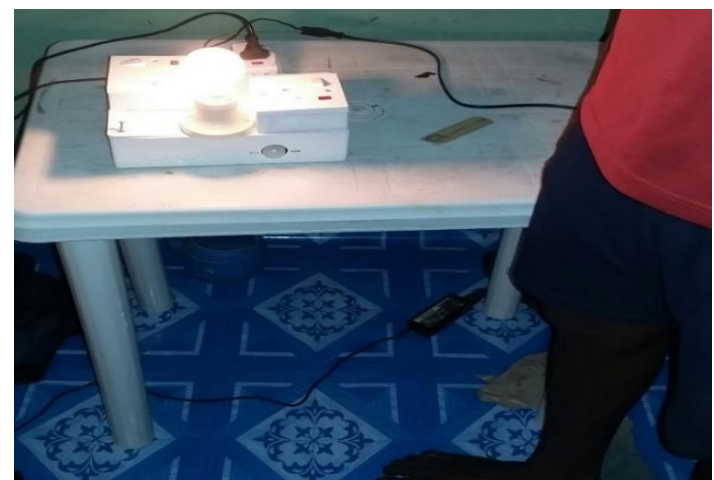

Fig. 5: Pictorial view of Bulb A lit on when there was an Occupant in the room at night.

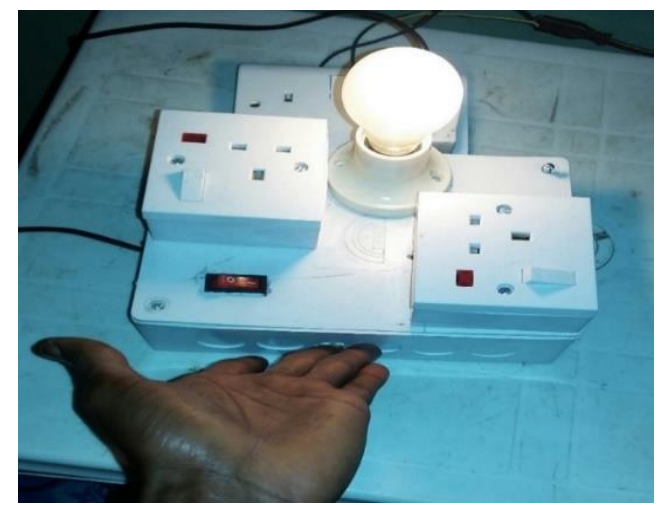

Fig. 6: Pictorial view of Bulb B lit on (though daytime) when there was an Occupant in the room

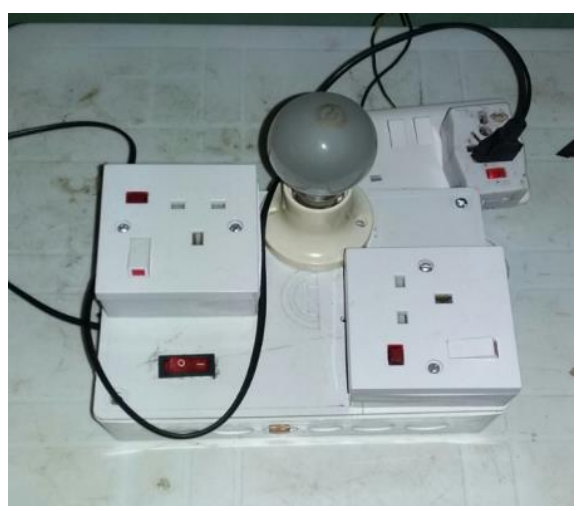

Fig. 7: Pictorial view of Bulb B turned off when there was no Occupant in the room. 
Table 1 shows the analysis of the test results. Regardless of the sensing unit output, the system remains OFF if the PIR is in state 0 (low output), which indicates the absence of an occupant. The fan requires two conditions to operate; the PIR output must be in a high state (state 1) and the room temperature must be greater than $35^{\circ} \mathrm{C}$. Likewise, the light in the room (represented as Bulb A) will only come up when the PIR is in state 1 (high output) and there is darkness in the room. Lastly, bulb B (representing the presence or absence of an occupant) would come up immediately the PIR is in state 1 (high output), indicating the presence of an occupant in the room. These conditions are programmed to suit the need of the occupant. But the user cannot change these conditions. This is an area for future improvement on the work. The device is programmed to shut down within five minutes after the last occupant leaves the room.

Table 1. The Test result of the Automatic Home/Office Power Control System

\begin{tabular}{|c|c|c|c|c|c|}
\hline \multirow{2}{*}{$p^{R}$} & \multirow{2}{*}{$x^{e}$} & \multirow{2}{*}{ "s } & \multicolumn{3}{|c|}{ Load } \\
\hline & & & Fan & Bulb A & Bulb B \\
\hline 0 & $>35$ & Dark & OFF & OFF & OFF \\
\hline 0 & $<35$ & Dark & OFF & OFF & OFF \\
\hline 0 & $>35$ & Light & OFF & OFF & OFF \\
\hline 1 & $<35$ & Dark & OFF & ON & ON \\
\hline 1 & $>35$ & Dark & ON & ON & ON \\
\hline 1 & $>35$ & Light & ON & OFF & ON \\
\hline 1 & $<35$ & Light & OFF & OFF & ON \\
\hline
\end{tabular}

\section{Conclusion}

This work presented a simple but robust automatic home power control device. The device is said to be simple because the design is not complicated, and the components used are readily available. It is robust because it automated the control of lighting points and fan socket source by auto-detecting human presence and application of other conditions such as the illumination level of the room before turning $\mathrm{ON}$ the light and the temperature state of the room before deciding whether to turn ON the fan or not. The device is designed to autodetect the presence of an occupant in the room through the PIR sensor and control the electrical appliances (lighting and fan source), hence reducing energy wastage.

Certain conditions must be met for the operation of lighting and the fan sources. The lighting comes up when the PIR sensor senses the presence of an occupant and there is relative darkness in the room, while the fan would work when the presence of an occupant is sensed by the PIR sensor and the temperature in the room is above 35 ${ }^{\circ} \mathrm{C}$. The device automatically switches OFF within five minutes after the last occupant leaves the room. The development of automated devices like this would contribute to a reduction in energy wastage and associated costs for consumers. The load scale which the device can control as well as a provision for the user to be able to change the condition of operation without recourse to the microcontroller are areas that can improve the efficiency of this system in future work.

\section{REFERENCES}

Adelakun, A., Adewale, A., Abdulkareem, A., \& Olowoleni, J. (2014). Automatic Control and Monitoring of Electrical Energy Consumption Using PIR Sensor Module. International Journal of Scientific \& Engineering Research, 5(5), 493-496.

Ashutosh, B. (2018). Performing Experiments With LM358. Engineers Garage. https://www.engineersgarage.com/electronicprojects/performing-experiments-with-lm358/

Chia, K. L., Choo, B. L., Lee, S. J., Luang, C. T. S., Tan, M. S., \& Truman, T. (2018). Robotic soldering of lead-free alloys. 2018 Pan Pacific Microelectronics Symposium (Pan Pacific), 1-10.

Ehiabhili, J. C., Oke, A. O., Olubosede, O., \& Olobatuyi, D. O. (2020). An Android Based Home Electrical Appliance Control System. FUOYE Journal of Engineering and Technology, 5(2), 80-83.

Iromini, N. A., Nafiu, A. S., \& Ajao, A. O. (2015). Automated Light Control Systems for Offices. International Journal of Engineering Sciences \& Emerging Technologies, 7(4), 701-706.

Johnson, D. O., Hassan, K. A., Okusanya, S. O., \& Oladapo, J. O. (2020). Solar Electricity System Design for Administrative Buildings. FUOYE Journal of Engineering and Technology, 5(1).

Mohammed, O. O., Otuoze, A. O., Salisu, S., Abioye, A. E., Usman, A. M., \& Alao, R. A. (2020). The Challenges and Panaceas to Power Distribution Losses in Nigeria. Arid Zone Journal of Engineering, Technology, and Environment, 16(1), 120-136.

Odat, E., Shamma, J. S., \& Claudel, C. (2017). Vehicle classification and speed estimation using combined passive infrared/ultrasonic sensors. IEEE Transactions on Intelligent Transportation Systems, 19(5), 1593-1606.

Otuoze, A. O., Usman, A. M., Mohammed, O. O., \& Jimoh, A. A. (2017). A review of smart grids deployment issues in developing countries. Arid Zone Journal of Engineering, Technology, and Environment, 13(6), 858.

Pont, M. J. (2002). Embedded C. Addison-Wesley Longman Publishing Co., Inc.

Rezoug, M. R., \& Krama, A. (2016). Control device for automatic orientation of a solar panel based on a microcontroller (PIC16f628a). AIP Conference Proceedings, 1758(1), 30046.

Shawn. (2019). LM7805 Voltage Regulator: Features, Comparisons, and more - Latest open tech from Seeed studio. https://www.seeedstudio.com/blog/2019/10/30/lm7805-voltageregulator-features-comparisons-lm317-and-more/ 